\title{
How can green building development promote the efficiency of carbon emission reduction in the construction industry? --Based on the dual perspective of industry and space
}

Bin Liao (D 511964583@qq.com )

Hunan University https://orcid.org/0000-0002-7663-6406

Li Lin

Hunan University

\section{Research Article}

Keywords: green building development, building carbon emission reduction efficiency, polarization effect, space panel Dubin model

Posted Date: April 28th, 2021

DOI: https://doi.org/10.21203/rs.3.rs-407698/v1

License: (1) This work is licensed under a Creative Commons Attribution 4.0 International License. Read Full License

Version of Record: A version of this preprint was published at Environmental Science and Pollution Research on September 10th, 2021. See the published version at https://doi.org/10.1007/s11356-02116380-2. 


\section{How can green building development promote the efficiency of carbon emission reduction in the construction industry? _ Based on the dual perspective of industry and space}

Bin Liao *, Li Lin

School of Economics and Trade, Hunan University, Changsha, China

511964583@qq.com,914449604@qq.com

* Correspondence: liaobin9612@hnu.edu.cn ; Tel.: initials) +86-185-1009-8467

Abstract: Green building development plays an important role in improving the efficiency of carbon reduction in the construction industry and accelerating the construction industry to achieve carbon neutrality goals. Based on the dual perspective of "industrial upgrading and space overflow", this paper integrates the topic of "green building development to promote carbon neutrality in the construction industry" into the cross-study of industrial economics and spatial economics,

Using China's provincial panel data from 2008 to 2019, use the intermediary adjustment model to prove how green building development builds an internal green supply and demand system in the industry to promote the efficiency of carbon emission reduction in the construction industryand use the space panel Dubin model to discuss the green building Development affects the spatial mechanism and attenuation boundary of the construction industry's carbon emission reduction efficiency. The study found that green building development has a positive effect on the efficiency of carbon reduction in the construction industry. And there is a clear "center-peripheral pattern" between green building development and the efficiency of carbon reduction in the construction industry. At the same time, the impact of green building development on the efficiency of carbon emission reduction in the construction industry exists "industry-space" two-dimensional mechanism, from the industrial perspective, green building development can activate the construction market form a green supply and demand system by promoting the green upgrading of supporting industries and stimulating the green consumption of the market, and finally realize the overall green upgrading of the construction industry. from the spatial level, the development of regional green buildings forms a new growth pole and enhances the carbon emission reduction efficiency of the construction industry in the region through polarization effect, inhibits the carbon emission reduction efficiency of the construction industry in neighboring areas, and this spatial polarization effect also shows obvious spatial attenuation characteristics. In the $1,000 \mathrm{~km}$, rangethe spillover effect is higher, while attenuation occurs outside the $1,000 \mathrm{~km}$ range. The results provide a theoretical basis and empirical evidence for the construction industry to improve the efficiency of carbon reduction and achieve industrial carbon neutrality.

Keywords: green building development; building carbon emission reduction efficiency; polarization effect; space panel Dubin model 


\section{INTRODUCTION}

With the intensification of global environmental pollution, the Earth's ecosystem is under unprecedented threat(Liao and Wang, 2020). In response to the growing climate challenge, countries around the world have developed "carbon neutral" targets as a guiding blueprint for their emissions reduction strategies over the next 30 years (Zhang et al., 2020). The construction industry has been a major battleground in academic and political discussions about improving the environment and reducing greenhouse gas emissions. According to previous research reports (Leung et al., 2015), Construction is a big carbon emitter in the industrial system, consuming about 40 percent of the world's energy and 33 percent of greenhouse gas emissions. However, In recent years, under the role of soft and hard incentive policies such as environmental protection subsidies and regulations, the construction industry has begun to transform green, and green building development has gradually become one of the mainstream models of construction activities (Oh et al., 2007).

The academic discussion on green building development originated from the United Nations Conference on Environmental Development, held in Rio de Janeiro, Brazil, in 1992. In the decades that followed, green buildings became a complex research system that considered energy conservation and environmental protection, residents' health, and clean production. Today, as the demand for low-carbon development in the construction industry continues to escalate, green buildings are becoming more widespread in many countries, and effectively controlling pollution emissions and energy waste in the construction industry through the implantation of environmental protection concepts throughout buildinglife cycle(Man et al., 2010; Todd et al., 2001). Existing literature has conducted in-depth research on the phenomenon and significance of green buildings (Eichholtz et al., 2013), But the research on green building development to lowcarbon development of the construction industry mainly focuses on the micro level (A and B, 2009), These studies only discuss how carbon emission trajectory optimization techniques(A et al., 2005; Castro-Lacouture et al., 2009), green building certification systems, and evaluation technologies(Circo, 2008; Potbhare et al., 2009) how to affect carbon emission reduction in the construction industry. At present, there is an urgent need for a medium and macro analysis and evaluation framework for the emission reduction performance of green building development to discuss the effects of the industrial policy and regional policy implementation of green building development.

In fact, from the point of view of industrial economics, the impact of green building development on the low-carbon development of the construction industry is not only reflected in the effect of technological progress on emission reduction. but also in the green upgrading of the construction industry structure and the activation of the green supply and demand market system in the construction industry. First of all, green building development will stimulate the construction industry supporting industry to develop more environmentally friendly building materials and green technology through the value chain, and then promote the formation of the green building supporting industry chain and the traditional construction industry chain green transformation. After that, the specialized division of labor in various departments of green buildings will further reduce the production cost of green buildings, form a scale effect and promoteinto the popularity of green buildings. Finally, the strength of environmental regulation and the continuous improvement of citizens' awareness of environmental protection will promote the formation of consumer pro-environmental consumption preferences, and activate the vitality of the green building consumption market, stimulate the demand for green buildings, the entire 
construction industry through demand-oriented completion of traditional non-green buildings to comprehensive green building development industry leap. Besides, the construction industry is a typical dual-intensive industry of labor and capital, and the development of green buildings will inevitably cause the flow and transfer of regional production factors(Zhong-Fu et al., 2008). So, does green building development have a "polarization effect" or a mutually beneficial "spillover effect" due to resource competition within the space? How this spacing effect affects the low-carbon development of the construction industry is also worthy of attention. Therefore, "how green building development can promote carbon neutrality in the construction industry through industrial green upgrading" is a complex economic problem with a multi-dimensional theoretical mechanism, which requires a new and interdisciplinary analysis framework to explain its process.

To this end, this article starts from the dual perspective of "industrial upgrading + spatial overflow", based on panel data from 30 provinces in China from 2008 to 2019, and measures the level of green building development through the Green Building Development Index (GBDI), Carbon emission reduction efficiency measures the emission reduction effect of the construction industry (CEEOCI). Use the intermediary model to explore the transmission mechanism of the two industries at the industry level, and use the spatial Dubin model to measure the spatial spillover effect and attenuation boundary of the two. Try to solve the following three key questions: (1) Can the development of green buildings improve the carbon emission efficiency of the construction industry? (2)What is the industry-level transmission mechanism for green buildings to promote carbon emission reduction in the construction industry? 3Does the impact of green building development on the carbon emission efficiency of the construction industry have spatial spillover characteristics? Is it spatial polarization or spatial overflow? What is its scope? Where is the boundary of the space overflow area?

The rest of this article is structured as follows. Part 2 contains a literature review. Section 3 outlines the methodology and data. Section 4 introduces the empirical results, answers those key questions above, and tests the results for robustness. Our conclusions and policy implications are introduced in Section 5 .

\section{LITERATURE REVIEW}

The construction industry is the pillar industry of the national economy. For a long time, the construction industry has made a great contribution to regional economic growth, but its extensive development model has also caused huge pollution emissions and energy consumption. With the increasingly prominent environmental problems, activating the potential of the construction industry to reduce emissions, exploring the low-carbon development path of the construction industry has become an important issue in the academic community. Carbon emission efficiency is an important perspective for studying the effects of emission reduction in the construction industry. There is a wide discussion on the definition and evaluation method of carbon emission efficiency in the construction industry.In terms of connotation definition, scholars discussed the emission reduction efficiency of the construction industry from different research perspectives and provided different efficiencies measurement perspectives, such as single-factor emission efficiency(Beckerman, 1992; Mielnik and Goldemberg, 1999), total-factor carbon emission efficiency(Halkos and Tzeremes, 2009), direct carbon emission efficiency(Lu et al., 2016), indirect carbon emission efficiency (Du et al., 2018)and Comprehensive carbon emission efficiency(Du et al., 2019). In terms of evaluation methods, considering the complexity of the construction industry's carbon emission system, scholars mainly use 
non-parametric methods when measuring the construction industry's carbon emission efficiency, using super-efficiency data envelopment analysis to study the production relationship between multiple inputs and outputs. Wang et al. (2015) used SBM-DEA to measure the carbon emission efficiency of China's construction industry and explains the characteristics of carbon emission efficiency. Song et al. (2019)considered the impact of environmental variables on the carbon emission measurement of the construction industry and used the staged SBM-DEA model to measure the carbon emission efficiency of the construction industry in various provinces in China. It was found that environmental interference factors caused abnormal fluctuations in the efficiency values of various provinces and cities. Therefore, The environmental impact should be excluded when measuring carbon emissions in the construction industry. Liang et al. (2020)used the three-stage DEA-Malmquist model to calculate the carbon emission efficiency of the construction industry in various regions of China from 2008 to 2017, and dynamically revealed the changes in the carbon emission efficiency of the Chinese construction industry.The above research has an important theoretical reference value for this article to discuss the carbon emission reduction efficiency of the construction industry. However, the main evaluation goal of the above research is to consider the maximization of carbon emission efficiency of the construction industry. Logically speaking, the maximization of carbon emission efficiency is not In the true sense of maximizing emission reduction efficiency, it is also difficult to characterize the guiding ideology of "carbon neutral" net emissions of zero. Therefore, this article will try to include the carbon emissions of the construction industry and the carbon absorption of the construction industry into the output goals, minimizing carbon emissions and maximizing carbon absorption as one of the target constraints, and use the three types of undesired output. Stage super-efficiency DEA model to evaluate the carbon emission efficiency of China's construction industry. The purpose of this is to ensure the elimination of environmental interference, while making up for the lack of a carbon emission reduction evaluation system structure in the construction industry, and to provide a theoretical reference for related research on carbon neutrality in the construction industry.

Green building development is the main path for the construction industry to achieve carbon neutrality and the long-term goal of sustainable urban development. In terms of the emission reduction effect of green buildings, scholars pay attention to the low-carbon concept and management methods of green buildings. Lu and Zhao (2014) pointed out that green building is a brand-new design concept, and its emission reduction effect is mainly derived from the green operation in the building design stage. Since then, In order to further implement the ideological guidance that green comes from design, scholars define green building design as a multi-objective optimization problem. After establishing multiple optimal objective functions including suitable living, environmental protection and low energy consumption, etc., Designed and solved the feasible solution of the implementation strategy of green building design through a genetic algorithm (A et al., 2005). Hwang and Tan (2012)analyzed the carbon emission reduction effects of green buildings from a cost perspective and formulated a green building project management framework from the aspects of green products, technology, management. At present, the research topics on the development of green buildings and the industrial level of carbon emission reduction in the construction industry are relatively general, and the only research is only to discuss the difference in carbon emission efficiency between green buildings and non-green buildings through simulation and other methods (Zhang et al., 2017). However, the specific mechanism of green building development on the carbon emission reduction efficiency of the construction industry and the temporal and spatial effects have not yet been reported. 
Compared with previous studies, the contributions of this study are: First, based on the dual perspective of "industrial upgrading-spatial spillover", This paper incorporates the theme of "green building development to promote carbon neutrality in the construction industry" into the research of industrial economics and space economics, providing a novel research perspective and a multidimensional mechanism analysis framework for the sustainable development of the construction industry (as shown in Figure 1). Secondly, this article explains how green building development accelerates the greening of supporting industrial chains and promotes green upgrading of the construction industry from the perspective of industrial structure upgrading and revealed the supply and demand side transmission mechanism of Low-carbon development of the construction industryFinally, the use of the spatial panel Dubin model proves the spatial polarization effect of green building development on the carbon emission reduction efficiency of the construction industry, answers questions such as the size of the polarization effect range and the decline boundary. finally, From the perspective of growth poles, it reveals the "carbon neutral" development stage of China's construction industry and provides a theoretical basis for stimulating the emission reduction potential of the construction industry and promoting carbon neutrality in the construction industry.

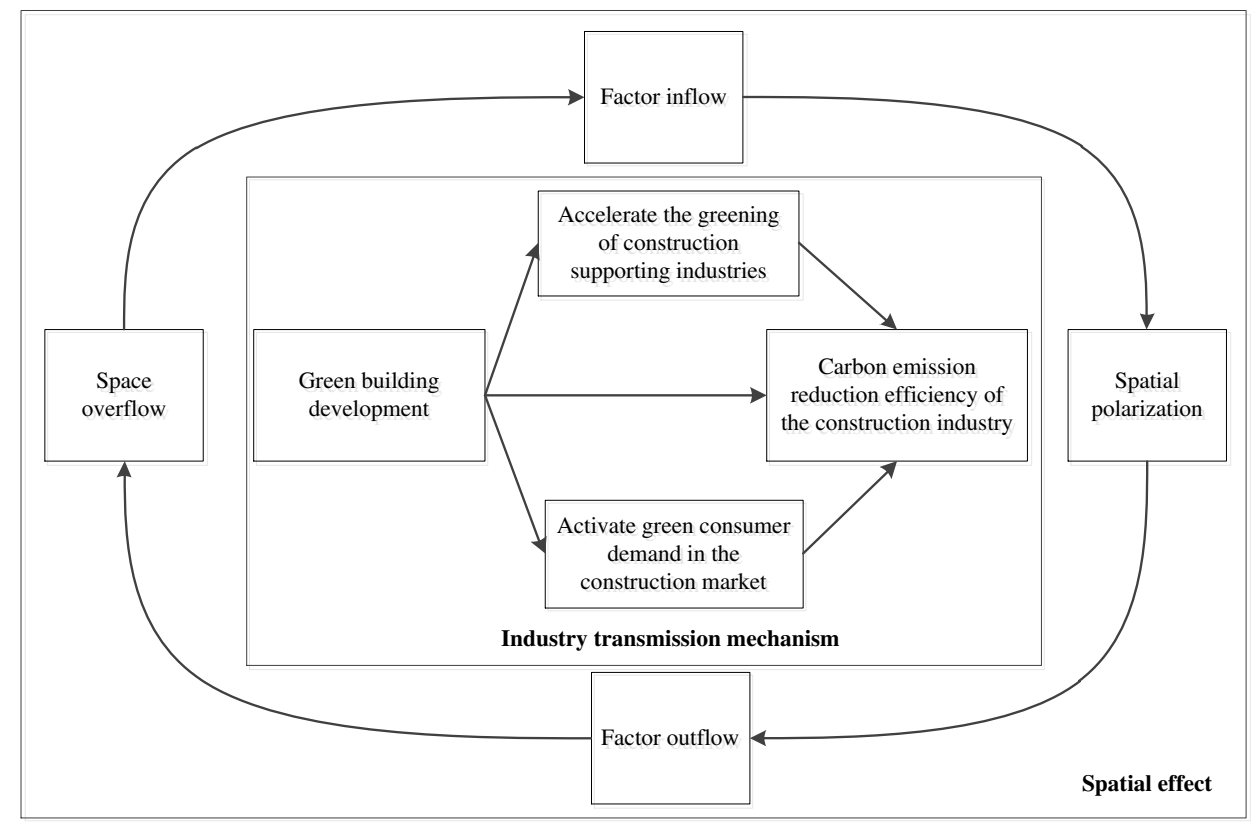

Figure 1. The analysis framework of the impact mechanism of green building development and the construction industry's carbon emission reduction efficiency under the dual perspective of "industry-space"

\section{METHODOLOGY AND DATA}

\subsection{METHODOLOGY AND DATA}

(1) Analysis of the transmission mechanism of green building development to improve the efficiency of carbon emission reduction in the construction industry

To explore the mechanism of green building development on the emission reduction effect of the construction industry, the following benchmark measurement model is constructed:

$$
\mathrm{CEEOCI}_{i t}=\mathrm{a}_{0}+\mathrm{a}_{1} G B D I_{i t}+\mathrm{a}_{2} X_{i t}+\varsigma_{i t}
$$


In formula (1), the subscripts $i$ and t represent provinces and years, respectively, CEEOCI represents the carbon emission reduction efficiency of the construction industry, GBDI represents the green building development index, $X_{i t}$ represents the control variable, and $\zeta_{i t}$ represents the disturbance item. According to the above analysis, green building development can optimize the internal supply-demand relationship of the industry by accelerating the green upgrade of supporting industrial chains and activating the green consumption demand of the construction market, thereby promoting the efficiency of carbon emission reduction in the construction industry. In order to further verify the above transmission mechanism, refer to previous studies Approach, construct the following mediating effect model(Zhonglin et al., 2004)

$$
\begin{gathered}
M_{i t}=\beta_{0}+\beta_{1} C_{E E O C I}+\beta_{2} X_{i t}+\varsigma_{i t} \\
\mathrm{CEEOCI}_{i t}=\lambda_{0}+\lambda_{1} \mathrm{GBDI}_{i t}+\lambda_{2} M_{i t}+\lambda_{3} X_{i t}+\varsigma_{i t}
\end{gathered}
$$

Among them, $M_{i t}$ represents intermediary variables such as the level of green development of the supporting industrial chain and market green demand, and the other corresponding variables have the same meaning as formula (1). If the coefficient $\alpha_{1}$ in formula (1), the coefficient $\beta_{1}$ in formula (2),

the coefficients $\lambda_{1}$, and $\lambda_{2}$ in formula (3) are all significant. meanwhile, $\lambda_{1}$ is less than $a_{1}$, it indicates that there is a mediating effect.

(2) Spatial correlation test

Construction activities between regions are not independent of each other, and often interact with the flow of production factors (Du et al., 2019). 因此, Ignoring the spatial correlation may lead to biases in the estimation results. At the same time, the previous analysis shows that there may be spatial effects in green building development and the carbon emission reduction efficiency of the construction industry. In order to improve the accuracy of the estimation results and test the spatial effects, this paper uses the spatial panel measurement model for empirical research. (Pellegrini and Grant, 2010). Before establishing a spatial measurement model, we must first conduct exploratory analysis and spatial statistical analysis of its spatial correlation. The exploratory analysis is done by ArcGIS software, and the spatial statistics usually use Global Moran's I for spatial autocorrelation test(Tiefelsdorf and Boots, 1997), the formula is as follows:

$$
I=\frac{m \sum_{i=1}^{m} \sum_{j=1}^{m} W_{i j}\left(X_{i}-\bar{X}\right)\left(X_{j}-\bar{X}\right)}{\sum_{i=1}^{m} \sum_{j=1}^{m} W_{i j} \sum_{i=1}^{n}\left(X_{i}-\overline{X_{i}}\right)^{2}}
$$

Among them, $m$ represents the number of samples, $X_{i} 、 X_{j}, \bar{X}, \overline{X_{i}}$ respectively represent the observation value of the $i$-th area, the observation value of the area around $i$, the overall average value and the average value of the observation value, and $W_{i j}$ represents the spatial weight matrix. 
$I<0$ represents positive spatial correlation; $I<0$ represents negative spatial correlation. The greater the absolute value of $I$, the greater the spatial correlation, and the smaller the absolute value of $I$, the greater the spatial randomness.

(3) Spatial measurement model setting

General spatial measurement models include a spatial autocorrelation panel model (SAR) that causes spatial autocorrelation due to spatial dependence and a spatial error panel model (SEM) that causes spatial autocorrelation due to spatial error terms. However, in many cases, the two mechanisms exist at the same time, so Lesage (2008)constructed a spatial Durbin model (SDM) that includes both of the above-mentioned transmission mechanisms. The specific expression is as follows:

$$
Y_{i, t}=\alpha_{0}+\rho W Y_{i, t}+\beta_{1} \Psi_{i, t}+\beta_{2} \Psi_{i, t}+\beta_{k} \sum_{k=3}^{n} X_{\text {control }}+\lambda_{i, t} \sum_{k=3}^{n} W X_{\text {control }}+\delta_{i, t}
$$

In formula (5), $Y_{i, t}$ is the Carbon reduction efficiency of the construction industry at the $\mathrm{t}$ time in the $i$ region; $\alpha_{0}$ is a constant term; $\rho$ is the spatial autoregressive coefficient; $W$ is the spatial weight matrix; $\Psi_{i, t}$ is the green building development index; $\beta_{1}$ is the elastic coefficient for the development of green buildings to the Carbon reduction efficiency of the construction industry, $\beta_{2}$ is the elasticity coefficient of the green building development index of the spatially related area to the carbon emission efficiency of the green building industry in the region; $X_{\text {control }}$ is a series of control variables, $\beta_{\mathrm{k}}$ is the elastic coefficient of the control variable; $\lambda_{i, t}$ represents the elasticity coefficient of spatially related regional control variables to the Carbon reduction efficiency of the construction industry in the region; $\delta_{i, t}$ is the random error term.

For the spatial Durbin model, since the spatial lag term it contains cannot well reflect the marginal returns of the variables, the partial differential method is adopted and the SDM is merged into the Siff matrix. Spatial effects are decomposed into direct effects, indirect effects and total effects. The specific process is as follows: Convert the general form of the SDM model into:

$$
Q=\left(I_{\mathrm{n}}-\rho W\right)^{-1} \alpha l_{n}+\left(I_{\mathrm{n}}-\rho W\right)^{-1}(\beta X+\lambda W X)+\left(I_{\mathrm{n}}-\rho W\right)^{-1} \varepsilon
$$

$$
\text { make } T(W)=\left(I_{\mathrm{n}}-\beta W\right)^{-1} H_{\mathrm{m}}(W)=T(W)\left(I_{\mathrm{n}} B_{m}+\lambda_{m} W\right) \text {, (6) can be converted into: }
$$

$$
Q=\sum_{m=1}^{k}(W) X_{m}+C(W) \alpha l_{n}+C(W) \varepsilon
$$

Convert formula (7) into matrix form: 


$$
\begin{aligned}
& {\left[\begin{array}{l}
Q_{1} \\
Q_{2} \\
\cdots \\
Q_{n}
\end{array}\right]=\sum_{m=1}^{k}\left[\begin{array}{cccc}
H_{m}(W)_{11} & H_{m}(W)_{12} & \mathrm{~K} & H_{m}(W)_{1 n} \\
H_{m}(W)_{n 1} & H_{m}(W)_{21} & \mathrm{~K} & H_{m}(W)_{2 n} \\
\mathrm{M} & \mathrm{M} & \mathrm{K} & \mathrm{M} \\
H_{m}(W)_{n 1} & H_{m}(W)_{n 2} & \mathrm{~K} & H_{m}(W)_{n m}
\end{array}\right]\left[\begin{array}{l}
X_{1 \mathrm{~m}} \\
X_{2 \mathrm{~m}} \\
\mathrm{M} \\
X_{n m}
\end{array}\right]} \\
& +T(W)\left(\varepsilon+\alpha l_{n}\right)
\end{aligned}
$$

In equation (4), the diagonal elements of the matrix on the right side of the equation reflect the average influence of the local independent variable on the local dependent variable, that is, the direct effect denoted as Directeffect $=\partial Q_{i} / \partial X_{i m}=H_{m}(W)_{i i}$; The elements on the off-diagonal line reflects the influence of the local independent variable on the surrounding dependent variable, that is, the spillover benefit, which is recorded as Indirecteffect $=\partial Q_{i} / \partial X_{j m}=H_{m}(W)_{i j}$; The total utility should be the sum of the direct benefit and the spillover effect, recorded as:

Totaleffect $=H_{m}(W)_{i i}+H_{m}(W)_{i j}$.

(4) Spatial weight matrix

The spatial weight matrix is a characterization of the interdependence and correlation between spatial units(Getis and Aldstadt, 2004) This paper uses the latitude and longitude to calculate the reciprocal of the Euclidean distance between the centroids of the central cities of two provinces to characterize the spatial dependence of the provinces(Punitha et al., 2005). Calculated as follows:

$$
\mathrm{W}_{i j}=\left\{\begin{array}{l}
1 / \mathrm{d}_{i j}, \text { if } \mathrm{d}_{i j} \geq \mathrm{d} \\
0, \quad \text { if } \quad \mathrm{d}_{i j}<\mathrm{d}
\end{array}\right.
$$

Formula (9), $\mathrm{d}_{\mathrm{ij}}$ is the geographic distance between the central city $\mathrm{i}$ and city $\mathrm{j}$ of the two provinces calculated based on the city's latitude and longitude. This paper uses the reciprocal distance between the central cities of two provinces as the spatial weight matrix to measure the spatial interaction between provinces.

(4) Geographical attenuation boundary of spatial effects

Generally speaking, the spatial correlation will gradually decrease with the increase of geographic distance, which will lead to the spatial spillover of the development of green buildings on the carbon emission efficiency of the construction industry to create a regional boundary. To this end, referring to the existing literature processing methods(Cavanagh et al., 2009), given different distance thresholds to construct the spatial weight matrix, and use the SDM model to return to it. which is:

$$
\mathrm{W}_{i j}=\left\{\begin{array}{l}
1 / \mathrm{d}_{i j}, \text { if } \mathrm{d}_{l}<\mathrm{d}_{i j}<\mathrm{d}_{u} \text { and } i \neq j \\
0, \quad \text { if } \mathrm{d}_{i j}<\mathrm{d}_{l} \text { or } \mathrm{d}_{i j}>\mathrm{d}_{u} \text { or } i=j>
\end{array}\right.
$$

In formula (10), $\mathrm{d}_{i j}$ represents the spatial distance between area $i$ and area $j, \mathrm{~d}_{l}$ represents the lower limit of the spatial threshold, $\mathrm{d}_{u}$ represents the upper limit of the spatial threshold. When it is within the threshold range, the weight matrix element is the reciprocal of the distance between the two places, and it is 0 if it is not within the threshold range. Considering that the shortest distance between 
the two provinces in China is $103 \mathrm{KM}$, the initial threshold is set to $200 \mathrm{~km}$, and $100 \mathrm{~km}$ is used as the progressive distance for analysis.

\subsection{DATA DESCRIPTION}

(1) Explained variable: carbon emission efficiency of the regional construction industry.

Taking into account the environmental interference in the evaluation process and the non-radial adjustment of input and output efficiency(Jesús et al., 2010), this paper uses the three-stage superefficiency SBM model with undesired output to measure the carbon emission reduction efficiency of the regional construction industry. First, this article divides the output into two parts: expected output and bad output. The expected output represents traditional economic output and carbon absorption output, expressed by the total output value of the regional construction industry and the area of newly added green space in the regional construction project. The environmentally unfavorable output is expressed by expressing the carbon emissions of the construction industry. It is accurately calculated based on the two dimensions of direct carbon emissions and indirect carbon emissions from the construction industry (Du et al., 2018). (Du et al., 2018). Secondly, this article chooses energy input, labor input, capital input and construction equipment input as input indicators; finally, Matlab software is used for calculation.

(2) Core explanatory variable: Green Building Development Index.

The green building development index is the original concept proposed in this article. We believe that the development of green buildings is a complex concept. It not only includes the area of green buildings that have been built to provide sustained benefits in terms of environmental protection, but also the quality and sustainability of green building development must be considered. Therefore, this article refers to the previous research on the method of reducing the dimension of multi-dimensional indicators(Sibson, 1987), and use the projection tracking method to calculate green building development level evaluation indicators from the following three dimensions: cumulative area of green buildings, newly approved green building projects and quality of completed green buildings.

(3) Conduction variable.

The level of green development of the construction supporting industry (gbsid) and the demand of the green building consumer market ( $\mathrm{gcmd}$ ) provides a transmission path for green building development to promote the emission reduction efficiency of the construction industry from the perspective of supply and demand. Among them, the green transformation of construction supporting industries are represented by the industrial added value of the four core supporting industrial chains of green buildings, including green building product production industry (including building special product manufacturing and building social general product manufacturing), green building manufacturing Industry (including the secondary processing, recombination and industrialized production of building traditional products), technical service industry chain (green building design, construction and operation), green building maintenance and recycling industry (including the spin-off of construction equipment products and materials), Remanufacturing and recycling(Potbhare et al., 2009).

Green consumption demand is usually used to express consumers' preference behavior and consumption habits for environmentally friendly products. This article measures the regional energy consumption per capita(Groot and Steg, 2009).

\section{(4)Control variable}

Industrial advantage (Indad), the proportion of the construction industry in the local industrial structure reflects the degree of local advantage of the construction industry to a certain extent. According to the theory of location economy and industrial structure, when the construction industry 
occupies a higher proportion of the industrial structure, it is more conducive to obtaining policy support and capital injection, so it is easier to develop new environmental protection technologies and lowcarbon industries. This article characterizes the proportion of the total output value of the construction industry in the GDP(Wang et al., 2015); per capita income (pggp) reflects the degree of local affluence, and the improvement of people's living standards will increase people's environmental awareness, which may improve The carbon emission reduction efficiency of the construction industry provides a social basis. This article is characterized by per capita GDP income (Uddin et al., 2020) An important manifestation of urbanization (urb) is the vigorous development of the construction industry. The construction industry in areas with high urbanization levels is generally more developed, and the carbon emission reduction efficiency is also higher. This paper uses the urbanization index to express it (Jiang, 2007). Opening up to the outside world is conducive to the entry of foreign capital, technology and management experience. On the one hand, it can make up for the lack of funds and technology for low-carbon development in the construction industry. On the other hand, external development may also turn the construction industry into a "pollution refuge" transfer channel. It is characterized by the proportion of local import and export trade value in GDP(Peng, 2020).

(5) Data source

The data on the green building development indicators for 2008-2016 comes from the Green Building Evaluation and Marking Network, and the data for the period from 16 to 19 is obtained through the compilation of the public information on the green building projects of the Provincial Construction Department. The rest of the index data comes from the 2009-2020 China Construction Industry Statistical Yearbook, China Industrial Statistics Yearbook, China Labor Statistics Yearbook, and China Population and Employment Statistics Yearbook. The indicators related to prices are all converted according to 2008 the actual amount. The map data comes from the National Basic Geographic Information Center.

\section{RESULTS}

\subsection{Preliminary STATISTICAL OBSERVATION AND EXPLORATORY ANALYSIS}

This paper uses the projection pursuit model and the three-stage super-efficiency SBM model with undesired output to calculate the green building development index and the construction industry's carbon emission reduction efficiency in 30 provinces from 2008 to 2016. Before in-depth research, it is necessary to use empirical data for preliminary statistical analysis in order to accurately grasp the basic relationship and general laws of green building development and the efficiency of carbon emission reduction in the construction industry. To this end, this paper draws Figure 2 with the green building development index of 30 provinces in 2008-2019 as the vertical axis and the carbon emission reduction efficiency of the construction industry as the horizontal axis. It can be seen that the development of green buildings is positively correlated with the carbon emission efficiency of the construction industry, indicating that the development of green buildings has promoted the development of the carbon emission efficiency of the construction industry in the region. 


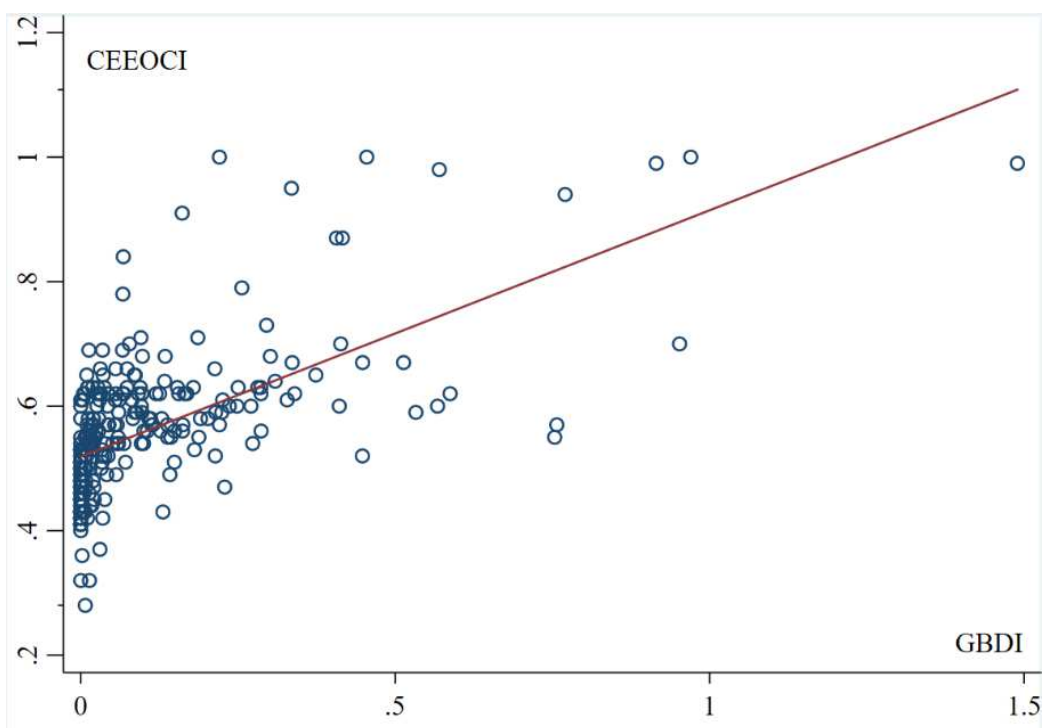

Figure 2 Scattered relationship between green building development and construction industry carbon emission reduction efficiency

To observe the spatial relationship between green building development and the carbon emission reduction efficiency of the construction industry, the ArcGIS 10.2 natural breakpoint classification method is used to draw the spatial pattern distribution map of the two, and follow the low-level green building development, medium-level green building development, and highlevel green building development. Green building development, low-level construction industry carbon emission reduction efficiency, medium-level construction industry carbon emission reduction efficiency, and high-level construction industry carbon emission reduction efficiency are graded, as shown in Figure 3. Observing Figure 3, we can see that the 2008 Green Building Development Index and the construction industry's carbon emission reduction efficiency have both consistency and spatial dislocation in the spatial distribution. The green building development index and the construction industry's carbon emission reduction efficiency in the southeast coastal areas are generally higher, while the central and western regions are relatively second, but both show a clear "center-periphery" pattern in space.In 2019, areas with high levels of carbon emission reduction efficiency in the construction industry tend to be more concentrated. Regional low-carbon building centers have gradually formed. Construction industries with high levels of carbon emission reduction efficiency are mainly distributed in Jiangsu and Zhejiang, Beijing and Tianjin, and the Central Plains. In the same year, the green building development index of 30 provinces increased significantly. While the Jiangsu and Zhejiang regions maintained high-level green building development, the central region gradually shifted from a low-level green building development area to a high-level green building development area, but still maintained the "center- Symmetrical spatial pattern of "periphery". This shows that there may be a spatial connection between the development of green buildings and the carbon emission reduction efficiency of the construction industry, and this spatial connection is disturbed by the imbalance of time and space.At the same time, this impact has a spatial polarization effect, that is, locations and regions where green building development activities are expanding will attract technology, talent, labor, capital and other green production factors from other regions to promote the low-carbon development of the construction industry and improve it. Construction industry carbon emission efficiency, while other regions are plundered by resources, which leads to the weakening of the 
local green building development level and the decrease of the construction industry's carbon emission reduction efficiency.

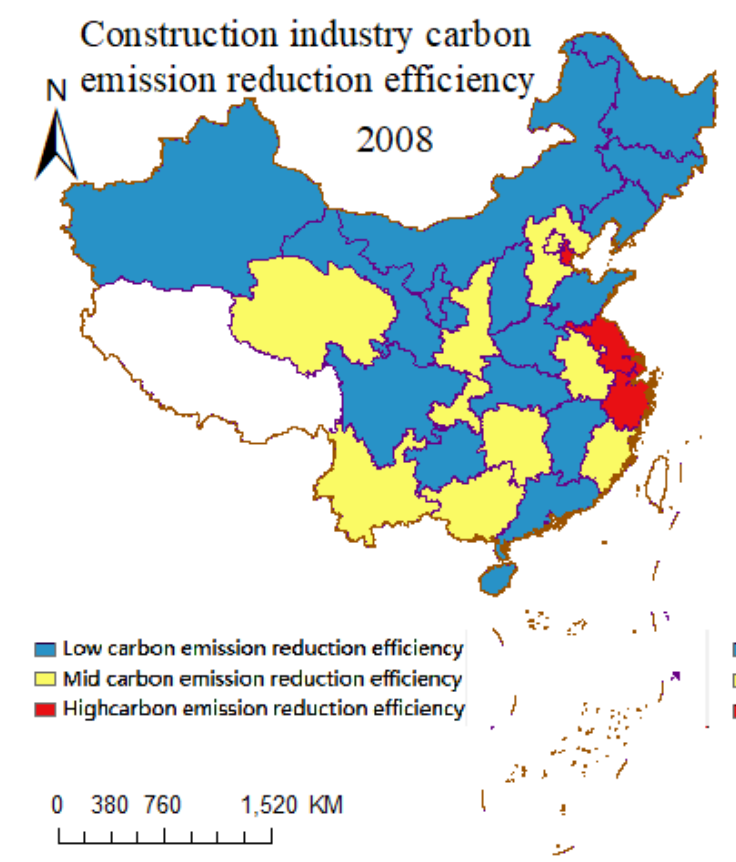

Construction industry carbon Nemission reduction efficiency
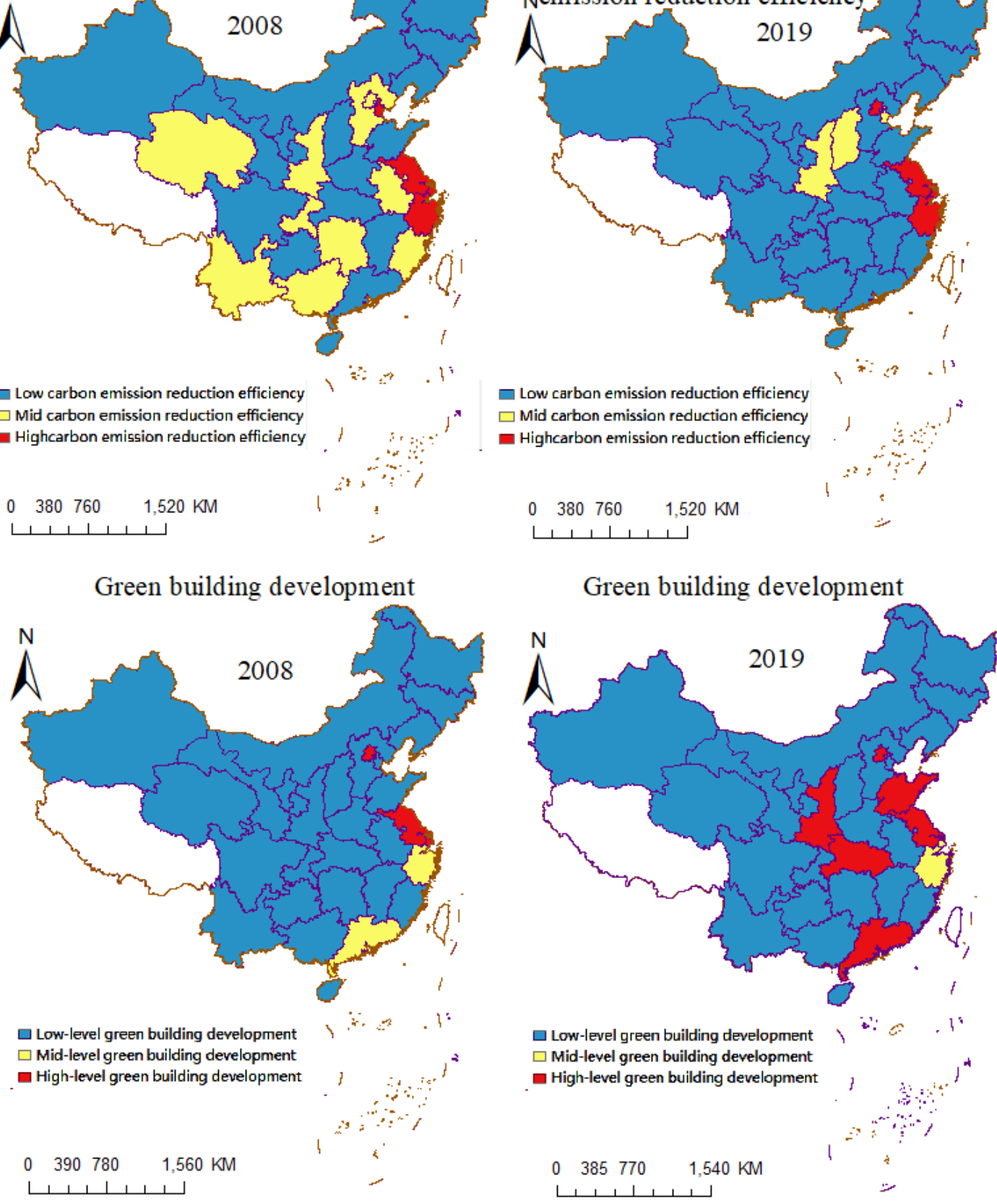

Figure 3 The spatial pattern of carbon emission reduction efficiency and green building development level in the construction industry in 2008 and 2019

\subsection{ANALYSIS OF THE TRANSMISSION MECHANISM OF GREEN BUILDING DEVELOPMENT AFFECTING THE EFFICIENCY OF CARBON EMISSION REDUCTION IN THE CONSTRUCTION INDUSTRY}

In order to further explore the correlation between green building development and the carbon emission reduction efficiency of the construction industry, and to verify the conduction mechanism of green building development affecting the carbon emission reduction efficiency of 
the construction industry, this article uses traditional panel OLS regression to study the relationship and conduction between the two mechanism. Through F test (41.99***) and Hausman test $(30.622 * * *)$ for model screening, it is found that the fixed effects model is suitable for estimating the relationship between green building development and the carbon emission efficiency of the construction industry. Therefore, the regression model of time and individual dual-fixation model is used, and the intermediary variables are successively added to test the transmission path. The results are shown in Table 1(1)-(7). It can be seen from (1) that the regression coefficient of green building development on the carbon emission reduction efficiency of the construction industry is 0.077 , and it is significant at the $1 \%$ confidence level, which indicates that there is a gap between the development of green buildings and the carbon emission efficiency of the construction industry. There is a significant positive correlation, and the development of green buildings can promote the efficiency of carbon emission reduction in the construction industry. From equations (2)-(4), it can be seen that there is a significant positive correlation between the green development level of the construction supporting industry, the green building development index, and the carbon emission reduction efficiency of the construction industry at the $1 \%$ confidence level. At the same time, the green development of supporting industries is added. After the level of this variable, the main effect of green building development on the carbon emission reduction efficiency of the construction industry decreased from 0.077 to 0.051 , which indicates that there is a significant intermediate between the green development level of the construction supporting industry and the emission reduction efficiency of the construction industry. Effect, that is to say, promoting the development of green building supporting industries is one of the transmission paths for green building to promote the efficiency of carbon emission reduction in the construction industry. Similarly, it can be seen from (5)-(7) that there is a significant positive correlation between the market's green consumption demand, the development level of green buildings, and the construction industry's carbon emission reduction efficiency at the $1 \%$ confidence level. At the same time, the market's green consumption demand is added. After one variable, the main effect of green building development on the carbon emission reduction efficiency of the construction industry decreased from 0.077 to 0.062 , which indicates that the market green demand has a significant intermediate effect between the development of green buildings and the emission reduction efficiency of the construction industry, that is to say Activating market green consumer demand is one of the paths for green buildings to promote carbon emission reduction efficiency in the construction industry. So far, it is clear that green building development can complete the emission reduction effect transmission by adjusting the green supply and demand market system of the construction market, and then promote carbon emission reduction in the construction industry. effectiveness.

Table 1. Benchmark regression results

\begin{tabular}{lccccccc}
\hline \multirow{2}{*}{ variable } & $(1)$ & $(2)$ & $(3)$ & $(4)$ & $(5)$ & $(6)$ & $(7)$ \\
\cline { 2 - 7 } & CEEOCI & CEEOCI & GBDI & CEEOCI & CEEOCI & GBDI & CEEOCI \\
\cline { 2 - 7 } GBDI & $0.077^{* * *}$ & & & $0.051^{* * *}$ & & & $0.062^{* * *}$ \\
& $(3.88)$ & & & $(2.68)$ & & & $(2.54)$ \\
gbsid & & $0.164^{* * *}$ & $0.271^{* * *}$ & $0.184^{* * *}$ & & & \\
& & $(4.16)$ & $(5.37)$ & $(3.15)$ & & & \\
gcmd & & & & & $0.284^{* * *}$ & $0.484^{* * *}$ & $0.316^{* * * *}$ \\
& & & & & $(3.67)$ & $(6.73)$ & $(5.62)$
\end{tabular}




\begin{tabular}{cccccccc} 
& $0.113^{* * *}$ & $0.142^{* *}$ & $0.321^{* *}$ & $0.12^{* * * *}$ & $0.175^{* * *}$ & & $0.163^{*}$ \\
Indad & $(3.64)$ & $(2.55)$ & $(2.31)$ & $(3.14)$ & $(6.14)$ & & $(1.96)$ \\
& $0.031^{* * *}$ & $0.048^{* * *}$ & $0.449^{* * *}$ & $0.026^{* * *}$ & $0.133^{* * *}$ & $0.413^{* * *}$ & $0.051^{* * *}$ \\
pgdp & $(3.47)$ & $(3.45)$ & $(4.37)$ & $(3.77)$ & $(4.72)$ & $(4.97)$ & $(4.96)$ \\
& $0.741^{* * *}$ & $0.541^{* *}$ & 0.506 & $0.631^{* * *}$ & $0.414^{* * *}$ & 0.521 & $0.623^{* *}$ \\
urb & $(5.36)$ & $(2.46)$ & $(1.18)$ & $(6.41)$ & $(5.35)$ & $(0.74)$ & $(2.34)$ \\
& $-0.259^{* * *}$ & $-0.196^{* * *}$ & 0.212 & $-0.259^{* * *}$ & $-0.175^{* * *}$ & 0.232 & -0.274 \\
open & $(-5.82)$ & $(-4.87)$ & $(0.91)$ & $(-6.37)$ & $(4.25)$ & $(1.14)$ & $(-4.37)$ \\
Fixed time & Yes & Yes & Yes & Yes & Yes & Yes & Yes \\
Fixed Individual & Yes & Yes & Yes & Yes & Yes & Yes & Yes \\
R2 & 0.314 & 0.624 & 0.714 & 0.426 & 0.629 & 0.671 & 0.467 \\
F & 137.29 & 141.63 & 151.03 & 147.27 & 164.62 & 174.13 & 146.36 \\
obs & 360 & 360 & 360 & 360 & 360 & 360 & 360 \\
Bootsrap test & & $\mathrm{Z}=4.62$ & $\mathrm{P}=0.000$ & $\mathrm{Z}=0.375$ & $\mathrm{P}=0.000$ \\
\hline
\end{tabular}

Note: $* * * * * *$ means passing the test of $1 \%, 5 \%$ and $10 \%$ significance respectively; $\mathrm{CEEOCI}=$ carbon emission reduction efficiency of the construction industry; GBDI = green building development index; gbsid=The level of green development of the construction supporting industry; gcmd= the demand of the green building consumer market; Indad=Industrial advantage;

$\operatorname{pggp}=$ per capita income; $u r b=$ urbanization; open=Open to the outside world $。$. The following table is the same

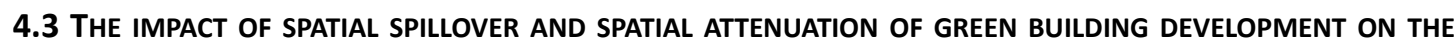 CARBON EMISSION EFFICIENCY OF THE CONSTRUCTION INDUSTRY}

(1) Spatial correlation analysis

Comprehensive theoretical analysis and preliminary statistical observations show that there is a significant spatial dependence between green building development and the carbon emission reduction efficiency of the regional construction industry, and this spatial dependence varies with distance. Therefore, this paper adopts the spatial panel Dubin model for theoretical analysis. Before this, combined with my country's regional green building development level and regional construction industry carbon emission reduction efficiency data from 2008 to 2019, based on the geographic distance matrix, the Moran's I value of these two indicators was calculated using stata 15 software, as shown in Table 2. It can be seen that between 2008 and 2019, the carbon emission reduction efficiency of my country's construction industry and the development of green buildings both showed a positive spatial correlation, and both passed the 5\% significance test. This shows that the carbon emission reduction efficiency of the regional construction industry and the development of green buildings are not randomly distributed, but a regular agglomeration distribution. This conclusion lays the foundation for the use of spatial measurement models.

Table 2. Carbon emission efficiency of regional construction industry and global Moran'sI value of green building

development

\begin{tabular}{ccccc}
\hline & \multicolumn{2}{c}{ CEEOC } & \multicolumn{2}{c}{ GBDI } \\
\cline { 2 - 4 } Time & Moran's I & Z-value & Moran's I & Z-value \\
\hline 2008 & $0.074^{* * *}$ & 2.873 & $0.241^{* * *}$ & 2.777 \\
2009 & $0.126^{* *}$ & 1.856 & $0.120^{* *}$ & 1.711 \\
2010 & $0.139^{* *}$ & 1.731 & $0.311^{* * *}$ & 3.526 \\
2011 & $0.119^{* *}$ & 1.834 & $0.208^{* * *}$ & 2.377
\end{tabular}




\begin{tabular}{lllll}
2012 & $0.144^{* * *}$ & 2.531 & $0.225^{* * *}$ & 2.592 \\
2013 & $0.183^{* *}$ & 2.313 & $0.196^{* * *}$ & 2.398 \\
2014 & $0.17^{1 * *}$ & 2.138 & $0.239^{* * *}$ & 2.576 \\
2015 & $0.191^{* *}$ & 2.208 & $0.317^{* * *}$ & 3.575 \\
2016 & $0.189^{* *}$ & 2.158 & $0.118^{* *}$ & 1.786 \\
\hline 2017 & $0.192^{* * *}$ & 2.523 & $0.162^{* * *}$ & 2.594 \\
\hline 2018 & $0.188^{* * *}$ & 2.651 & $0.152^{* * *}$ & 2.611 \\
\hline 2019 & $0.193^{* * *}$ & 2.741 & $0.157^{* * *}$ & 2.852 \\
\hline
\end{tabular}

(2) Spatial measurement analysis

After controlling the regional and temporal effects, this article separately analyzes the spatial fixed effects (sf), time fixed effects (tf), and time-space double fixed effects (stf) of the three spatial measurement models of SAR, SEM, and SDM. The investigation, the results are shown in Table 3(1)-(9). It can be seen that under the three spatial measurement models, the spatial autoregressive coefficient and the spatial error coefficient are all positive numbers, and they have passed the $1 \%$ significance test. This shows that the positive effect of green building development on the carbon emission reduction efficiency of the construction industry is also significant on the scale of space research. It also shows that the impact of green building development in various regions on the building carbon emission reduction efficiency is not independent of each other, but has a certain degree. Spatial correlation. This is consistent with the Moran's I result asked above. The carbon emission efficiency of the regional construction industry is affected by neighboring areas, and this effect is related to geographic distance.

Table 3. Spatial panel regression results

\begin{tabular}{|c|c|c|c|c|c|c|c|c|c|}
\hline \multirow{2}{*}{ 变量 } & (1) & (2) & (3) & (4) & (5) & (6) & (7) & (8) & (9) \\
\hline & SARsf & SARtf & SARstf & SEMsf & SEMtf & SEMstf & SDMsf & SDMtf & SDMstf \\
\hline \multirow{2}{*}{ GBDI } & $0.076^{* * *}$ & $0.246^{* * *}$ & $0.111^{* * *}$ & $0.093^{* * *}$ & $0.187^{* * *}$ & $0.096^{* * *}$ & $0.118^{* * *}$ & $0.132^{* * * *}$ & $0.098^{* * *}$ \\
\hline & $(3.05)$ & $(6.52)$ & $(4.20)$ & (3.74) & $(4.71)$ & $(3.82)$ & $(4.21)$ & (4.43) & $(3.49)$ \\
\hline \multirow{2}{*}{$\rho$} & $-0.106^{* * *}$ & $-0.131^{* * *}$ & $-0.106^{* * *}$ & -2.258 & -0.164 & -0.185 & $-0.134^{* * *}$ & -0.153 & $-0.141^{* * *}$ \\
\hline & (7.24) & $(-6.17)$ & $(-8.38)$ & $(-4.71)$ & $(-4.32)$ & $(-4.25)$ & $(4.65)$ & $(-0.51)$ & $(5.49)$ \\
\hline \multirow{2}{*}{ Indad } & $0.146^{* * *}$ & $0.169^{*}$ & $0.092^{*}$ & $0.231^{*}$ & $0.231^{*}$ & $0.13^{*}$ & $0.163^{*}$ & $0.160^{* *}$ & $0.253^{* *}$ \\
\hline & $(4.15)$ & $(1.78)$ & $(1.72)$ & (1.77) & (1.86) & (1.89) & $(1.67)$ & (1.87) & (1.94) \\
\hline \multirow{2}{*}{ pgdp } & $0.036^{* * *}$ & 0.138 & 0.018 & 0.049 & $0.034^{* * *}$ & 0.005 & 0.028 & 0.069 & 0.075 \\
\hline & ( 3.41$)$ & $(1.53)$ & $(0.16)$ & (5.38) & (3.36) & $(0.42)$ & $(0.45)$ & (0.64) & $(0.83)$ \\
\hline \multirow{2}{*}{ urb } & $0.541^{* * *}$ & 0.357 & 0.045 & $0.731^{* * *}$ & 0.18 & 0.033 & $0.267^{* *}$ & 0.254 & $0.273^{*}$ \\
\hline & $(7.11)$ & $(0.67)$ & $(0.20)$ & (5.29) & (1.41) & $(0.16)$ & (1.93) & (1.58) & (1.67) \\
\hline \multirow{2}{*}{ open } & -0.259 & $-0.249^{*}$ & $-0.220^{* * * *}$ & $-0.199^{* * *}$ & $-0.221^{* * *}$ & $-0.196^{* * *}$ & -0.133 & -0.254 & $-0.179^{* * *}$ \\
\hline & $(-6.26)$ & $(-1.86)$ & $(-5.14)$ & $(-4.86)$ & $(-4.93)$ & $(-4.63)$ & $(-3.85)$ & $(-3.16)$ & $(4.69)$ \\
\hline \multirow{2}{*}{$\mathrm{W}^{*} \mathrm{GBDI}$} & & & & & & & $-0.731^{* *}$ & $-0.789^{* *}$ & $-0.777^{* *}$ \\
\hline & & & & & & & $(-2.55)$ & $(-2.31)$ & $(-1.99)$ \\
\hline \multirow{2}{*}{ W*instr } & & & & & & & $-1.431^{* * *}$ & $-1.642^{* * *}$ & $-1.381^{* * *}$ \\
\hline & & & & & & & $(4.69)$ & $(3.14)$ & $(2.70)$ \\
\hline \multirow{2}{*}{$W^{*}$ pgdp } & & & & & & & 0.871 & 0.099 & $0.119^{* * *}$ \\
\hline & & & & & & & $(5.31)$ & (7.07) & (7.93) \\
\hline $\mathrm{W}^{*}$ urb & & & & & & & -0.452 & $-0.573^{*}$ & $-0.538^{* *}$ \\
\hline
\end{tabular}




\begin{tabular}{|c|c|c|c|c|c|c|c|c|c|}
\hline & & & & & & & $(-1.71)$ & $(-1.69)$ & $(-1.99)$ \\
\hline \multirow{2}{*}{$\mathrm{W}^{*}$ open } & & & & & & & 0.042 & 0.040 & 0.040 \\
\hline & & & & & & & $(0.61)$ & $(0.78)$ & $(0.68)$ \\
\hline $\mathrm{R} 2$ & 0.297 & 0.463 & 0.310 & 0.305 & 0.432 & 0.484 & 0.477 & 0.536 & 0.623 \\
\hline $\log -\mathrm{L}$ & 467.31 & 301.01 & 488.62 & 471.75 & 304.37 & 487.91 & 405.58 & 416.89 & 436.53 \\
\hline obs & 360 & 360 & 360 & 360 & 360 & 360 & 360 & 360 & 360 \\
\hline
\end{tabular}

Comparing the fitting effects of the three measurement models, the goodness of fit of the spatial dubin model (SDM) is generally higher than that of the spatial lag model (SAR) and the spatial error model (SEM). In addition, through the LM (Robust) test, Wald test, LR test, and Hausman test (Table 4), the spatial lag model (SAR) and the spatial error model (SEM) can test the effect of green building development on the carbon emission reduction efficiency of the construction industry. Spatial spillover effect. The Wald and LR tests found (Table 4) that in the spatial matrix weight matrix, both Wald test and LR test significantly rejected the null hypothesis, indicating that there may be deviations in using the SAR model or the SEM model to investigate the spatial spillover effects of green building development. Therefore, after comparing the maximum likelihood value sum (Log-L) and the adjusted coefficient of determination (R2) of the three types of spatial measurement models, this paper chooses to use the space-time dual fixed Dubin model for green building development and construction industry carbon The spatial spillover effect of emission reduction efficiency and its attenuation boundary are analyzed.

Table 4. Hausman, Wald test and LR test of the model

\begin{tabular}{clcc}
\hline test & Statistics & Moran's I & Z-value \\
\hline LM (lag) test & $30.038^{* * *}$ & Wald_spatial_lag & $92.740^{* * *}$ \\
Robust LM (lag) test & $14.352^{* * * *}$ & LR_spatial_lag & $128.160^{* * * *}$ \\
LM(error) test & $49.228^{* * *}$ & Wald_spatial_error & $86.880^{* * *}$ \\
Robust LM(error) test & $19.209^{* * *}$ & LR_spatial_error & $121.430^{* * *}$ \\
Hausman test of & $30.622^{* * * *}$ & Hausman test of & $62.930^{* * *}$ \\
Panel regression & & Space measurement \\
\hline
\end{tabular}

In order to further discuss the spatial effect between green building development and the efficiency of carbon emission reduction in the construction industry, according to formula (6)formula (8), the impact effect of Model 10 in Table 3 is decomposed into direct impact, spillover impact and total impact. The utility of using the partial differentiation method is shown in Table 5.

From the results in Table 5, it can be seen that the direct impact of green building development is 0.078 , the indirect impact is -0.098 , and the total impact is -0.020 , and it has passed the significance test of at least $5 \%$. This indicates that there is a spatial polarization effect in the development of green buildings, and this polarization effect has promoted the improvement of the carbon emission reduction efficiency of the local construction industry. This discovery provides a spatial theoretical explanation for the development of green buildings to promote the low-carbon development of the construction industry. However, it is also worth noting that while green building development promotes the low-carbon development of the local construction industry, it has a significant hindrance to the low-carbon development of the construction industry in the surrounding areas, and the negative external effects produced are greater than the local effects. From the perspective of the growth pole theory, the possible reason for this phenomenon is: the low-carbon transformation of the construction industry is the result of the joint effect of the capital market and environmental regulatory policies, and the "profitability" of capital and labor will promote the 
production of low-carbon development in the construction industry Factors flow to developed regions that are environmentally friendly and have a strong industrial green foundation. Regions with a higher level of green building development will absorb capital and labor from the construction industry in backward areas, which is needed to improve the efficiency of carbon emission reduction in the construction industry. The "siphon effect" of the clean elements of China will weaken its low-carbon development ability. Under the action of the cumulative effect of the cycle, the level of green development and the efficiency of carbon emission reduction between regions will gradually form a "middle-peripheral" pattern.

Among the control variables, the industrial advantage (indad) has a negative spillover effect on the surrounding areas, which shows that the development of the construction industry has obvious resource space competition(Dai and Chen, 2010). When the local construction industry develops low-carbon technologies, policies and industries will coordinate through welfare policies to attract a large number of talents and investors. When the construction industry in multiple regions simultaneously improves carbon emission efficiency, they may compete for talent, capital, and capital. The hijacking of labor has hindered the development of the construction industry in the surrounding areas. Urbanization (urb) has a negative spillover effect on the surrounding areas while promoting the carbon emission efficiency of the local construction industry(Dorning et al., 2015), indicating that there is a negative spatial correlation between the development of urbanization between regions. Judging from these two results, the current stage of low-carbon development in China's construction industry has huge resource competition in space, and this competition is related to the low-carbon development of the intergovernmental competition. Opening to the outside world has inhibited the carbon emission reduction efficiency of the local construction industry and has also positively promoted the surrounding areas. This conclusion supports the "pollution paradise hypothesis" (Peng, 2020). The construction industry is a heavy pollution industry and a high-profit industry. Opening to the outside world will provide investment channels for foreign investment and also create new channels for pollution transfer. Therefore, pollution is accompanied by The transfer of capital to places with a developed degree of opening to the outside world has hindered the improvement of local carbon emission efficiency.

Table 5. Spatial effect decomposition

\begin{tabular}{cccc}
\hline & Direct effect & Indirect effect & Total effect \\
\hline \multirow{2}{*}{ GBDI } & $0.078^{* * *}$ & $-0.098^{* *}$ & $-0.020^{*}$ \\
& $(2.65)$ & $(2.10)$ & $(-1.75)$ \\
\multirow{2}{*}{ Indad } & $0.351^{* *}$ & $-1.488^{* * *}$ & $-1.488^{* * *}$ \\
& $(1.98)$ & $(-3.19)$ & $(-3.19)$ \\
\multirow{2}{*}{ pgdp } & 0.013 & $0.091^{* * *}$ & $0.104^{* * *}$ \\
& $(0.67)$ & $(5.38)$ & $(5.14)$ \\
urb & $0.394^{*}$ & $-0.215^{* *}$ & $0.179^{* * *}$ \\
& $(1.76)$ & $(2.13)$ & $(-4.40)$ \\
open & $-0.211^{* * *}$ & $0.117^{* *}$ & $-0.094^{* *}$ \\
& $(-4.23)$ & $(2.15)$ & $(-2.05)$ \\
\hline
\end{tabular}

(3) Spatial effect attenuation boundary measurement

According to formula (10), the spatial weight matrix obtained at different progressive distances is brought into the spatial measurement model for continuous regression, and 35 spatial spillover 
estimation coefficients and $\mathrm{t}$ statistic values are obtained, and the test is passed at least at the $10 \%$ significance level. The relationship between the spatial spillover coefficient and the distance change is shown in Figure 4.

It can be seen from Figure 4 that the negative spatial spillover effect (ie polarization effect) of green building development on the carbon emission reduction efficiency of the regional construction industry shows an overall attenuation trend as the distance increases, from -0.351 at $200 \mathrm{Km}$ to 0.011 at $1800 \mathrm{Km}$. Among them, the echo effect from $200 \mathrm{Km}$ to $1000 \mathrm{Km}$ shows a slow decline. The provinces within this distance are mostly located in the eastern and central regions. The level of green building development and the carbon emission efficiency of the construction industry are both high, and the level of urbanization and construction industry development in various regions The difference is also small. Therefore, various provinces and cities are more intense in the stealing of low-carbon development resources in the construction industry, and the polarization phenomenon of "one mountain cannot tolerate two tigers" is prone to appear. After $1000 \mathrm{Km}$, the polarization effect has significantly decreased. This distance is roughly the distance from the eastern coastal area to the southwest, northeast, and northern provinces and cities. As the distance increases, the greenness of coastal areas has a significant impact on the construction industry in inland areas. The ability to grab resources has declined and the polarization effect has been declining. After 1600km, an area with a rapid decrease in the spatial coefficient appears and the significance becomes weaker, indicating that the polarization effect of green building development on the carbon emission reduction efficiency of the regional construction industry has greatly reduced the impact on the more distant northwest inland areas.

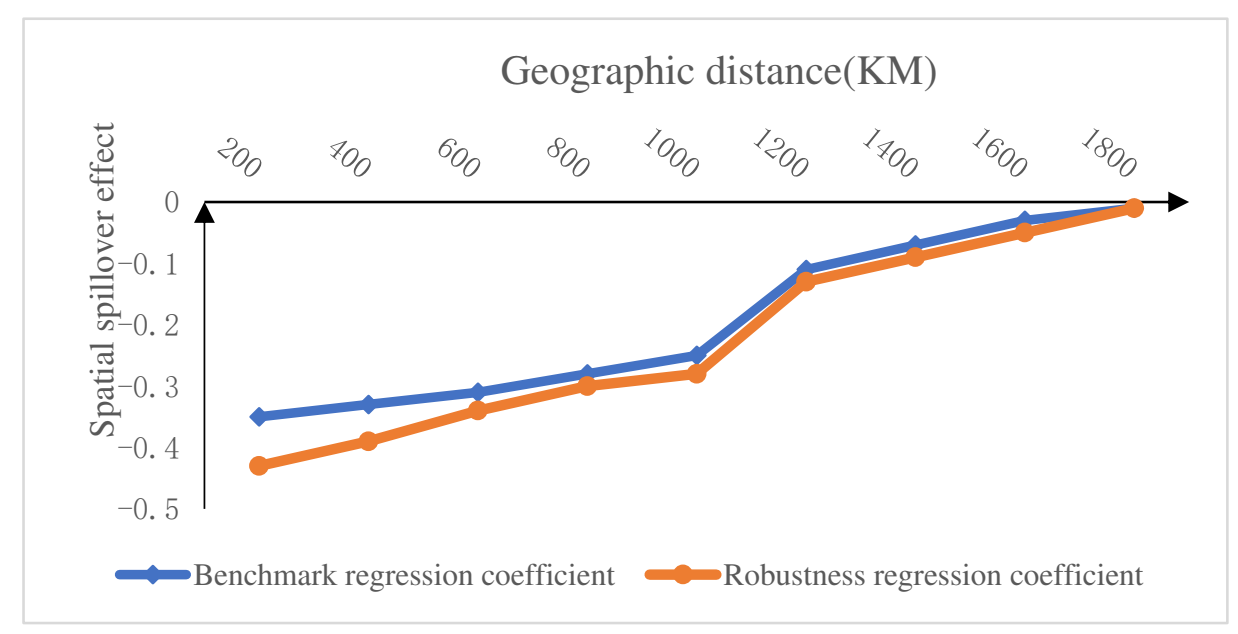

Figure 4. Green building development spillover coefficient changes with geographic distance

\subsection{ROBUSTNESS TEST}

In order to further verify the robustness of the model constructed in this paper, 5000 samplings of the Boostrap method are used to test the robustness of the mediation effect, and the result is that Boostrap significantly rejects the null hypothesis, as shown in Table 1. At the same time, the robustness of spatial effects is tested from the perspective of different spatial weight matrices. By constructing an adjacent weight matrix to replace the spatial weight matrix with geographical features mentioned above, it was found that in the case of changing the spatial weight matrix, the signs and significance levels of the spatial term coefficients, green building development index and control variables are almost no Changes are only different in the degree of impact. In addition, 
comparing the fitting effects of the three spatial models, the spatial Doberman model is still better, and the geographic attenuation distance gap of the spillover effect tends to overlap at 1800KM, which indicates that the constructed model has good robustness.

\section{CONCLUSIONS AND PROSPECTS}

\subsection{CONCLUSION}

Activating the emission reduction potential of the construction industry is the key to reducing pollution emissions and promoting carbon neutrality, and green building development is the main transformation path for improving the emission reduction efficiency of the construction industry. In the process of promoting the low-carbon development of the construction industry through green building development, a macro-theoretical framework is needed to explain the correlation, transmission mechanism, and spatial influence between the two. This article attempts to construct an analysis framework for green building development to promote the carbon emission efficiency of the construction industry from the dual perspective of "industrial upgrading + spatial overflow" for the first time. Based on the panel data of 30 provinces in China from 2008 to 2019, it reveals the influence mechanism of green building development to promote the efficiency of carbon emission reduction in the construction industry in multiple dimensions and discusses the reasons for the formation of spatial effects and the attenuation boundary in depth. The main conclusions are as follows:

Firstlly, China's green building development has a positive spatial correlation with the carbon emission reduction efficiency of the regional construction industry, and has obvious spatial agglomeration characteristics, mainly "high-high agglomeration" and "low-low agglomeration". Besides, both indicators show a "center-periphery" stepped distribution. The eastern coastal area is a high-value agglomeration area for green building development and construction carbon emission reduction efficiency, the western inland is a low-value agglomeration area, and the central area is the Transition zone.

Secondly, green building development promotes the construction industry's carbon emission reduction efficiency in a two-dimensional mechanism of industry and space. At the industrial level, green building development can change the relationship between supply and demand within the industry by accelerating the green upgrade of the construction supporting industry and stimulating the green consumer demand in the construction market, thereby promoting a comprehensive green upgrade of the industry. At the spatial level, green building development will attract green production factors for low-carbon development in the construction industry through spatial polarization effects, thereby enhancing the efficiency of carbon emission reduction in the construction industry. And this polarization effect has the characteristic of attenuating with the increase of geographic distance. In the range of 200-1000 kilometers, the polarization effect is relatively high and relatively stable; but after 1000 kilometers, the polarization effect shows a continuous attenuation trend. Beyond 1,600 kilometers, the polarization effect declines rapidly and its importance diminishes.

\subsection{POLICY RECOMMENDATIONS}

The findings of this article have the following policy implications:

For the industry, this article reveals the supply-demand transmission mechanism of green building development. Industry-related departments can start from the perspective of supply-side reform and demand-side incubation. On the one hand, by accelerating the cultivation of green building supporting industries, and actively guiding the low-carbon upgrading of traditional 
supporting industries in the construction industry to optimize the green level of the industrial supply market, specifically, it can be appropriate Provide subsidies for the green transformation of traditional supporting industries, establish a green technology sharing platform, and strengthen the green industry chain supervision system. On the other hand, the construction industry should also increase the market promotion of green building products and the popularization of environmental protection concepts, improve the formation of the industry's green supply chain system and the exploration of potential green consumer customers in the construction market, and drive the overall green transformation of the construction industry through demand Eventually, the two sides of supply and demand will exert efforts to form a joint force to promote the overall green transition of the construction industry.

For government departments, they should focus on the spatial polarization of green building development to promote the efficiency of carbon emission reduction in the construction industry. First of all, we must not blindly pursue the high-level development of green buildings, which will lead to vicious competition for resources between regions. Second, local governments should strengthen collaboration, actively establish a platform for the coordinated development of lowcarbon development in the construction industry, strengthen the exchange and cooperation of advanced low-carbon building technologies and management concepts, and realize the overflow and sharing of green development resources. Third, we must focus on improving the quality of external development and transforming the model, strengthening the supervision and inspection of foreign investment in the construction industry, strengthening the level of environmental supervision, and preventing or curbing the "pollution refuge" phenomenon caused by the low-carbon development of the construction industry.

Need further research. Although we have studied the development of green buildings and the carbon emission efficiency of the construction industry from a new perspective, and have drawn some interesting conclusions. However, some restrictions should be resolved in the future. First, limited by the availability of data, this article only selects data from 30 provinces in China, and calls on scholars to expand the sample of this study through urban panel data and test the hypothesis of this study on a smaller spatial scale. Second, the low-carbon development of the construction industry and the improvement of carbon emission efficiency are key ways for countries to achieve carbon neutrality. However, the construction industry is also an important part of the real economy. The industrial chain involved can be extended to various fields. Therefore, I hope that future research will explore how the development of green buildings affects the carbon emission efficiency of the construction industry from the perspective of the power industry, construction industry, industry and other multi-industry chains.

\section{Ethical Statement}

(1)Informed Consent

All participants informed consent form

(2)Conflict of Interest

The authors confirm that there are no known conflicts of interest associated with this publication and there has been no significant financial support for this work that could have influenced its outcome.

\section{(3)Ethical Considerations}

There are no ethical issues in this article 


\section{Authors Contributions}

Bin Liao: Conceptualization, Methodology, Investigation, Writing -original draft, Software, Formal analysis Writing - review \& editing, Project, administration, Validation, Visualization... Lin Li: Resources, Funding acquisition, Supervision

\section{Declaration of competing interest}

The authors declare that they have no known competing financial interests or personal relationships that could have appeared to influence the work reported in this paper.

\section{Funding}

This research is supported by the National Social Science Foundation of China (Nos.17ZDA081) and Hunan Provincial Social Science Foundation of China (No.18ZWA20).

\section{Data availability}

Materials described in the manuscript, including all relevant raw data, will be freely available to any researcher wishing to use them for non-commercial purposes, without breaching participant confidentiality.

\section{References}

A, H.H.A., B, S.F.A.N., 2009. Developing a green building assessment tool for developing countries - Case of Jordan. Building and Environment 44(5), 1053-1064.

A, W.W., A, R.Z., B , H.R.D., 2005. Applying multi-objective genetic algorithms in green building design optimization - ScienceDirect. Building and Environment 40(11), 1512-1525. Beckerman, W., 1992. Economic growth and the environment: Whose growth? whose environment? World Development 20.

Castro-Lacouture, D., Sefair, J.A., Flórez, L., Medaglia, A.L., 2009. Optimization model for the selection of materials using a LEED-based green building rating system in Colombia. Building \& Environment 44(6), 1162-1170.

Circo, C.J., 2008. Using Mandates and Incentives to Promote Sustainable Construction and Green Building Projects in the Private Sector: A Call for More State Land Use Policy Initiatives. Penn State Law Review.

Dai, Y.A., Chen, C., 2010. Spatial Econometric Analysis of Regional Differences in China's Construction Industry Development. Statistics \& Information Forum.

Dorning, M.A., Koch, J., Shoemaker, D.A., Meentemeyer, R.K., 2015. Simulating urbanization scenarios reveals tradeoffs between conservation planning strategies. Landscape and Urban Planning 136, 28-39.

Du, Q., Lu, X., Li, Y., Wu, M., Bai, L., Yu, M., 2018. Carbon Emissions in China's Construction Industry: Calculations, Factors and Regions. International Journal of Environmental Research \& Public Health 15(6).

Du, Q., Zhou, J., Pan, T., Sun, Q., Wu, M., 2019. Relationship of carbon emissions and economic growth in China's construction industry. Journal of Cleaner Production 220(MAY 20), 99-109.

Eichholtz, P., Kok, N., Quigley, J.M., 2013. THE ECONOMICS OF GREEN BUILDING. Review of economics and statistics.

Groot, J.D., Steg, L., 2009. Mean or green: which values can promote stable proenvironmental behavior? Conservation Letters 2(2), 61-66. 
Halkos, G.E., Tzeremes, N.G., 2009. Exploring the existence of Kuznets curve in countries' environmental efficiency using DEA window analysis. Ecological Economics 68(7), 21682176.

Hwang, B.G., Tan, J.S., 2012. Green building project management: obstacles and solutions for sustainable development. Sustainable Development 20(5), 335-349.

Jiang, C., 2007. Empirical Research on the Relationship between the Process of Urbanization and the Development of Construction Industry in China. Construction Economy.

Leung, T., M., Chau, C., K., W., Y., 2015. A review on Life Cycle Assessment, Life Cycle Energy Assessment and Life Cycle Carbon Emissions Assessment on buildings (vol 143, pg 395, 2015). Applied energy.

Liang, X., Lin, S., Bi, X., Lu, E., Li, Z., 2020. Chinese construction industry energy efficiency analysis with undesirable carbon emissions and construction waste outputs. Environmental Science and Pollution Research, 1-15.

Liao, B., Wang, T., 2020. Research on Industrial Waste Recovery Network Optimization: Opportunities Brought by Artificial Intelligence. Mathematical Problems in Engineering 2020.

Lu, B., Zhao, Q., 2014. Development and Application of Green Building Design. Applied Mechanics \& Materials 584-586, 840-844.

Lu, Y., Cui, P., Li, D., 2016. Carbon emissions and policies in China's building and construction industry: Evidence from 1994 to 2012. Building and Environment 95(JAN.), 94103.

Man, H.B., Li, J., Duan, H.Y., Wang, L.C., Wang, X.E., 2010. Study on the countermeasures of low-carbon transformation of construction industry in China. IEEE.

Mielnik, O., Goldemberg, J., 1999. Communication The evolution of the "carbonization index" in developing countries. Energy Policy 27(5), 307-308.

Oh, S.K., Kwak, K.S., Sun, Y.S., Kwon, S.W., 2007. A Study on Test Methods for Performance Appraisal of Root Barrier Appling to Green Roofs. Journal of the Korean Ceramic Society 7(1), 183-208.

Pellegrini, P.A., Grant, J.T., 2010. Policy Coalitions in the U.S. Congress: A Spatial Duration Modeling Approach. Geographical Analysis 31(1), 45-66.

Peng, X., 2020. Strategic interaction of environmental regulation and green productivity growth in China: Green innovation or pollution refuge? Science of The Total Environment 732, 139200.

Potbhare, V., Syal, M., Korkmaz, S., 2009. Adoption of Green Building Guidelines in Developing Countries Based on U.S. and India Experiences. Journal of Green Building 4(2), 158-174.

Sibson, J.R., 1987. What is Projection Pursuit? Journal of the Royal Statistical Society 150(1), 1-37.

Song, J., Chen, C., Wang, X., Zhen, H.U., Management, S.O., 2019. Research on Construction Industry Carbon Emission Efficiency Based on Three-Stage Super Efficient DEA Model. Environmental Science \& Technology.

Tiefelsdorf, M., Boots, B., 1997. A Note on the Extremities of Local Moran's Iis and Their Impact on Global Moran's I. Geographical Analysis 29(3). 
Todd, JA, Crawley, Geissler, Lindsey, 2001. Comparative assessment of environmental performance tools and the role of the Green Building Challenge. BUILDING RES INFORM 2001,29(5)(-), 324-335.

Uddin, M.A., Akter, R., Al-Amin, M., Rahman, M.S., Ferdausy, S., 2020. How Do Socially Responsible Human Resource Management And Voluntary Green Behavior Influence Organizational Competitiveness? Studies in Business \& Economics 15.

Wang, B.B., Xiao, H.F., Sun, H., 2015. Analysis of the Economic Growth and Industrial Advantage of the Silk Road Economic Belt Provinces. Journal of Guangdong University of Finance \& Economics.

Zhang, L., Wu, J., Liu, H., 2017. Turning green into gold: A review on the economics of green buildings. Journal of Cleaner Production 172(pt.2), 2234-2245.

Zhang, N., Zhang, X., Lei, M., Yang, Y., 2020. Multiagent Collaborative Governance for Targeted Poverty Alleviation from the Perspective of Stakeholders. Complexity 2020, 8276392.

Zhong-Fu, L.I., Jian-Shuang, F., Yi-Yue, W., 2008. The Research on Structure Adjustment and Upgrading of Construction Industry in China. Construction Management Modernization. Zhonglin, W., Lei., Z., Jietai, H., Hongyun, L., 2004. Intermediary Effect Test Procedure and Its Application. Acta Psychologica Sinica (05), 614-620. 
Figures

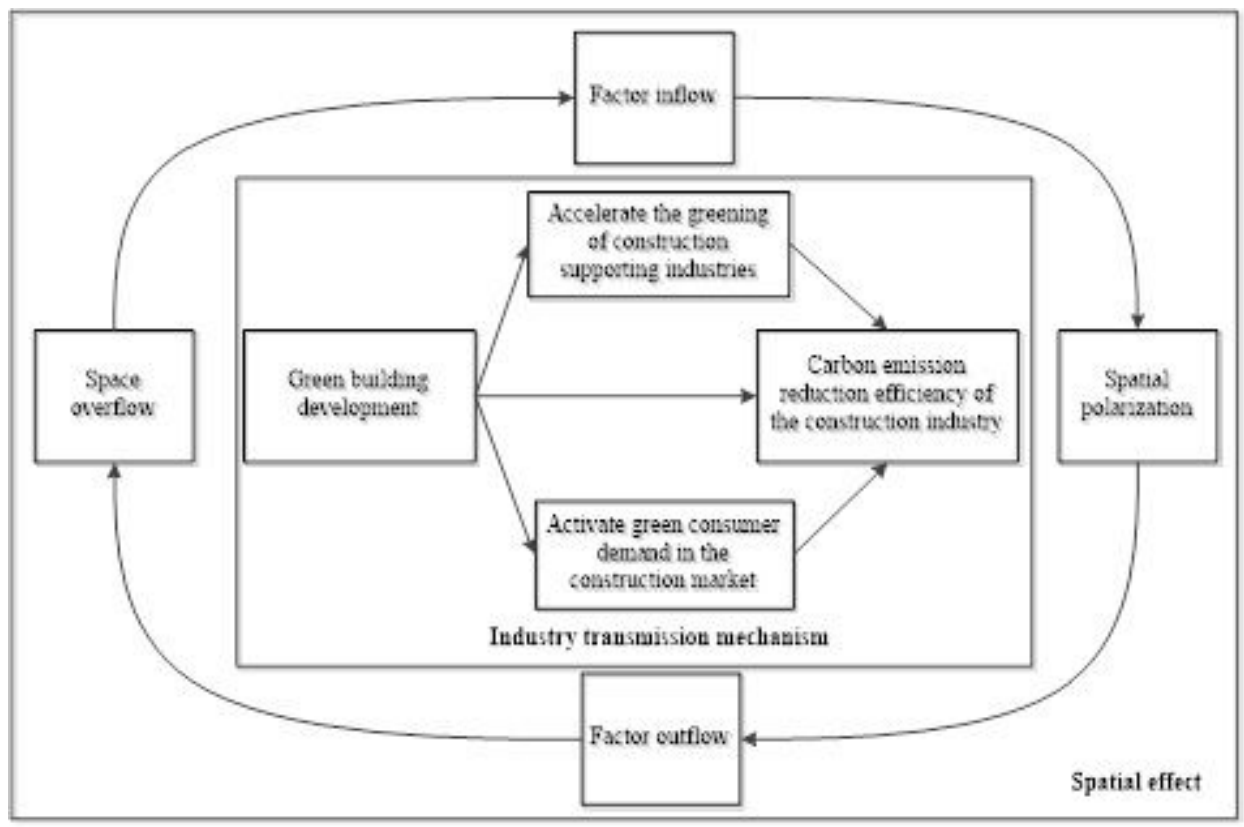

Figure 1

The analysis framework of the impact mechanism of green building development and the construction industry's carbon emission reduction efficiency under the dual perspective of "industry-space"

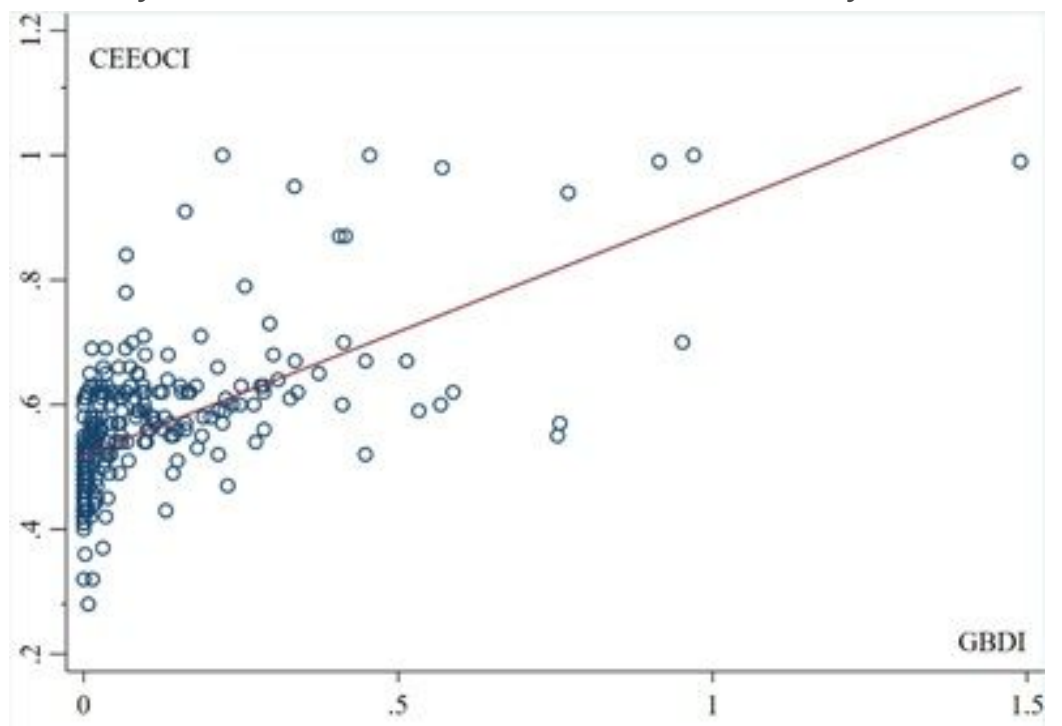

\section{Figure 2}

Scattered relationship between green building development and construction industry carbon emission reduction efficiency 
Construction industry carbon $\mathrm{N}$ emission reduction efficiency
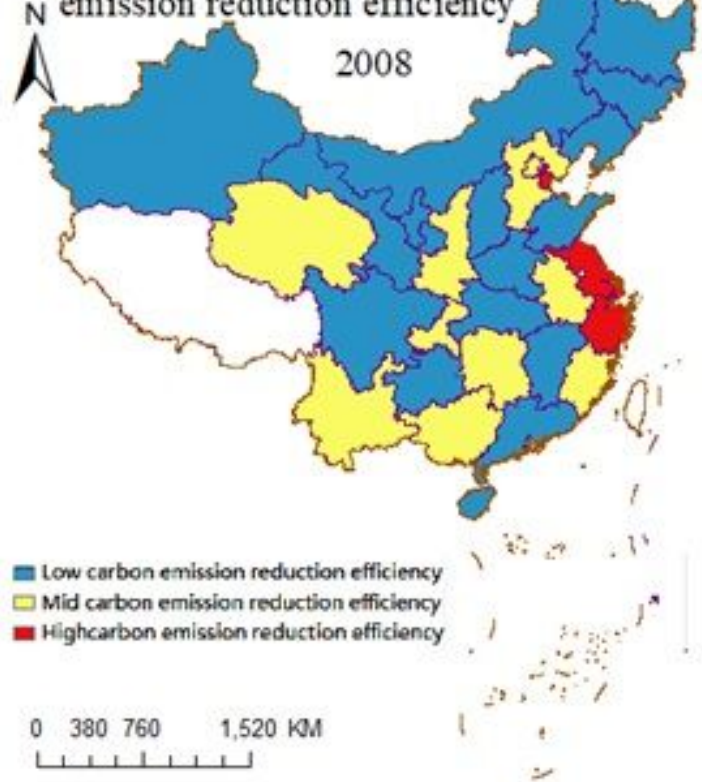

Green building development

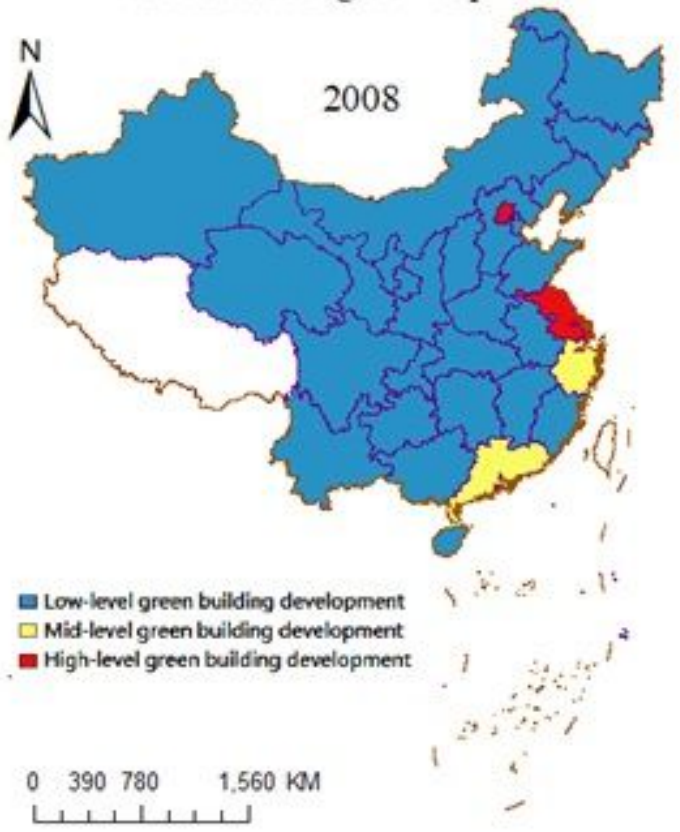

Construction industry carbon Nemission reduction efficiency

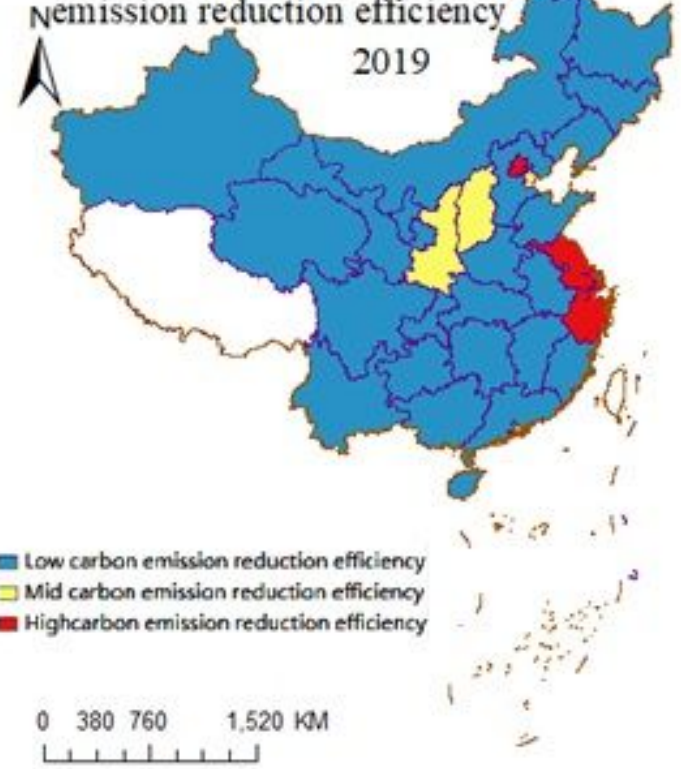

Green building development

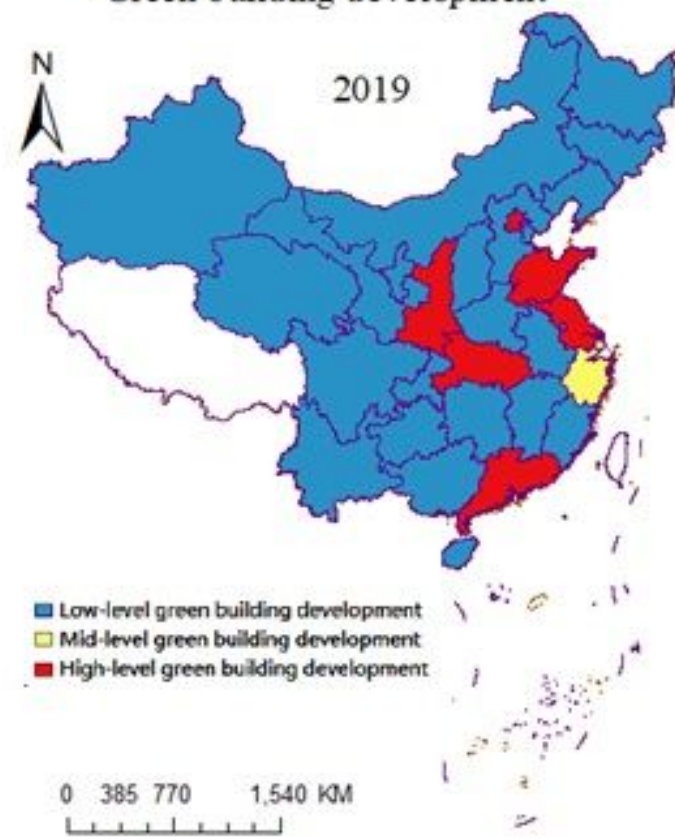

\section{Figure 3}

The spatial pattern of carbon emission reduction efficiency and green building development level in the construction industry in 2008 and 2019. Note: The designations employed and the presentation of the material on this map do not imply the expression of any opinion whatsoever on the part of Research Square concerning the legal status of any country, territory, city or area or of its authorities, or concerning the delimitation of its frontiers or boundaries. This map has been provided by the authors. 


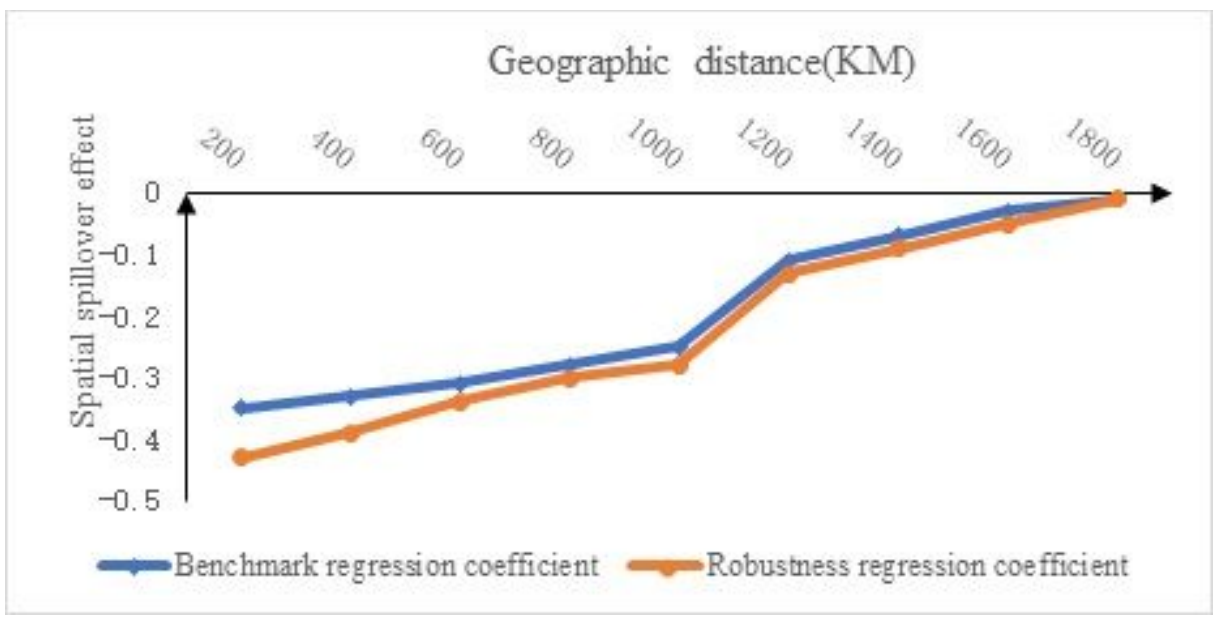

Figure 4

Green building development spillover coefficient changes with geographic distance 